\title{
Effect of polishing instruments and polishing regimens on surface topography and phase transformation of monolithic zirconia: An evaluation with XPS and XRD analysis
}

Al-Haj Husain, Nadin ; Camilleri, Josette ; Ȯzcan, Mutlu

\begin{abstract}
PURPOSE: Polishing procedures might alter monolithic zirconia (MZ) surface resulting in phase changes that can be deleterious for clinical performance and antagonist tooth wear. This study investigated the topographical features and phase transformation in $\mathrm{MZ}$ after polishing with different regimens simulating the clinical workflow. MATERIALS AND METHODS: MZ specimens (Katana Zirconia HT, Kuraray-Noritake) $(12 \times 12 \times 1.8$ $\mathrm{mm}(3)$ ) were grinded and polished using one of the five systems assessed: BG: Silicone carbide polishers (Brownie, Greenie, Super Greenie); CG: Diamond impregnated ceramic polisher kit (Ceragloss); EV: Synthetically bonded grinder interspersed with diamond (EVE Kit); SL: Urethane coated paper with aluminium oxide grits (Soflex Finishing and Polishing System Kit) and DB: Diamond bur $(8 \mu \mathrm{m})$. Polished specimens were initially roughened with $220 \mu \mathrm{m}$ diamond burs (Grinding Bur-GB) $(10 \mathrm{~s}, 160.000160,000 \mathrm{rpm})$ and considered for baseline measurements. Polishing regimens were performed for $10 \mathrm{~s}$ using a slow-speed hand piece under water-cooling except for SL, in a custom made device (750 g; 5000 and 75,000 rpm). Surface roughnesses, phase changes (XRD) were assessed, surface characterization was performed (SEM, EDS). RESULTS: The highest roughness was obtained with the EV system $(1.11 \mu \mathrm{m})$ compared to those of other systems $(0.13-0.4 \mu \mathrm{m})\left(\mathrm{p} \theta\right.$ and minor peak at $34.94^{\circ} 2 \theta$. While GB, CG, $\mathrm{EV}, \mathrm{SL}$ and DB exhibited a peak shift to the left, BG demonstrated a right peak shift on the $2 \theta$ scale. Monoclinic phase change was not noted in any of the groups. CONCLUSION: All polishing methods, except BG, exhibited a peak shift towards the lower angles of the 2-theta scale. Since the peak shifts were in the order of fractions of an angle they are attributed to stress formation rather than a phase change in the material. Thus, all polishing systems tested may not be detrimental for the phase transformation of MZ. EV system resulted in the highest roughness and none of the polishing regimens restored the polishability to the baseline level.
\end{abstract}

DOI: https://doi.org/10.1016/j.jmbbm.2016.07.025

Posted at the Zurich Open Repository and Archive, University of Zurich ZORA URL: https://doi.org/10.5167/uzh-128124

Journal Article

Accepted Version

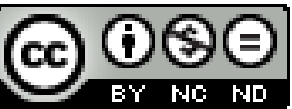

The following work is licensed under a Creative Commons: Attribution-NonCommercial-NoDerivatives 4.0 International (CC BY-NC-ND 4.0) License.

Originally published at: 
Al-Haj Husain, Nadin; Camilleri, Josette; Özcan, Mutlu (2016). Effect of polishing instruments and polishing regimens on surface topography and phase transformation of monolithic zirconia: An evaluation with XPS and XRD analysis. Journal of the Mechanical Behavior of Biomedical Materials, 64:104-112.

DOI: https://doi.org/10.1016/j.jmbbm.2016.07.025 
Effect of polishing instruments and polishing regimens on surface topography and phase transformation of monolithic zirconia: An evaluation with XPS and XRD analysis

Nadin Al-Haj Husain ${ }^{a,}{ }^{,}$, Josette Camilleri ${ }^{b}$, Mutlu Özcan ${ }^{a}$

aUniversity of Zürich, Dental Materials Unit, Center for Dental and Oral Medicine, Clinic for Fixed and Removable Prosthodontics and Dental Materials Science, Plattenstrasse 11, $\mathrm{CH}-8032$, Zurich, Switzerland

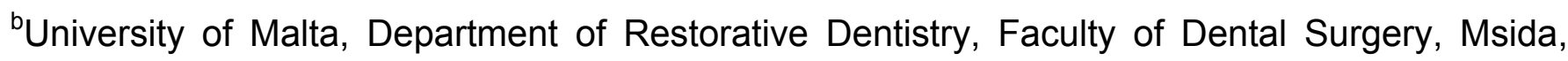
Malta

Short title: Topographical change and phase transformation in zirconia after polishing

*Corresponding author at: Mutlu Özcan, Prof. Dr.med.dent., Ph.D., Dental Materials Unit, University of Zurich, Center for Dental and Oral Medicine, Clinic for Fixed and Removable Prosthodontics and Dental Materials Science, Plattenstrasse 11, CH 8032, Zurich, Switzerland. Tel: +41 44 6343251; fax: +41 44 6344305. E-mail address: mutluozcan@hotmail.com 


\begin{abstract}
Purpose: Adjustments and polishing of monolithic zirconia (MZ) following cementation are often necessary to eliminate the premature contacts and minimize antagonistic tooth or dental material wear. The polishing procedures might alter surface properties of $M Z$ resulting in phase changes that can be deleterious for the long-term clinical performance. This study investigated the topographical features and phase transformation in $M Z$ after polishing with different regimens simulating the clinical workflow.
\end{abstract}

Materials and Methods: MZ specimens (Katana Zirconia HT, Kuraray-Noritake) (12 mm x 12 $\mathrm{mm} \times 1.8 \mathrm{~mm}$ ) were obtained and highly polished. Specimens were grinded and polished using one of the five systems assessed: BG: Silicone carbide polishers (Brownie, Greenie, Super Greenie); CG: Diamond impregnated ceramic polisher kit (Ceragloss); EV: Synthetically bonded grinder interspersed with diamond (EVE Kit); SL: Urethane coated paper with aluminium oxide grits (Soflex Finishing and Polishing System Kit) and DB: Diamond bur (8 $\mu \mathrm{m}$ ). Polished specimens were initially roughened with $220 \mu \mathrm{m}$ grit diamond burs (Grinding Bur-GB, Intensiv) (10 s, $160.000 \mathrm{rpm}$ ) and considered for baseline measurements in order to detect the polishing efficacy. Each step in all polishing systems was performed for $10 \mathrm{~s}$ using a slow-speed hand piece under water-cooling $(50 \mathrm{ml} / \mathrm{min})$ except for SL. Polishing was performed in a custom made device under $750 \mathrm{~g}$ load, with rpm ranging between 5.000 to 30.000 depending on the manufacturer`s instructions. For DB a high-speed hand piece was used at $75.000 \mathrm{rpm}$. After ultrasonic cleaning, surface roughnesses were measured using a Profilometer. Phase changes were assessed by X-ray diffraction (XRD) analysis. Surface 
characterization was performed using scanning electron microscopy (SEM) and energy dispersive spectroscopy (EDS).

Results: The highest roughness was obtained with the EV system $(1.11 \mu \mathrm{m})$ compared to those of other systems $(0.13-0.4 \mu \mathrm{m})(\mathrm{p}<0.05)$. Compared to baseline specimens $(03.02 \mathrm{wt} \%$; 00.66 at\%), EDS analysis showed increased weight and atomic percentages of yttrium for each polishing method (04.93-05.35 wt\%; 01.41-01.63 At\%), except for BG (02.3 wt\%; 00.45 At\%). Main peak of tetragonal zirconia was observed (01-070-4432) at $30.13^{\circ} 2 \theta$ and a minor peak at $34.94^{\circ} 2 \theta$. While GB, CG, EV, SL and DB exhibited a peak shift to the left, BG demonstrated a right peak shift on the $2 \theta$ scale. No monoclinic phase change was noted after any of the polishing systems.

Conclusion: All polishing methods, except BG, exhibited a peak shift towards the lower angles of the 2-theta scale. Since the peak shifts were in the order of fractions of an angle they are attributed to stress formation rather than a phase change in the material. Thus, all polishing systems tested may not be detrimental for the phase transformation of MZ. EV system resulted in the highest roughness and none of the polishing regimens restored the polishability to the baseline level.

Keywords: Monolithic zirconia; Phase transformation; Polishing; Tribology; Y-TZP; XRD 


\section{Introduction}

Zirconium dioxide (hereafter: zirconia) has been used in orthopedic total hip arthroplasty for decades (Christel et al., 1989) and was introduced in dentistry as a material for endodontic posts, implant-abutments and frameworks for crowns and fixed dental prosthesis (FDP) (Manicone et al., 2007). Favorable mechanical characteristics such as wear resistance, high elasticity modulus, hardness (1140 Knoop Value), superior toughness (6-10 MPa m1/2) and fracture strength $(>1000 \mathrm{MPa}$ ) enabled the widespread of monolithic zirconia (MZ) (British Standards Institution 1995; Guzzato et al., 2004; Kelly and Denry, 2008) as an alternative to bilayered ceramics indicated for FDPs, eliminating the commonly experienced chipping or fracture failures (Raigrodski et al., 2012). The high fracture resistance allows a minimal occlusal thickness of $0.5 \mathrm{~mm}$ to withstand bite forces in the molar region contributing to the biological benefit of tooth substance preservation (Nakamura et al., 2015). Despite the strength under compression, it remains a brittle material with limited tensile strength (Probster and Diehl, 1992) being susceptible to stress corrosion in humid environment (Lilley, 1990).

Clinical hip implant failures showed evidence of Low temperature Degradation (LTD), surface degradation and wear on opposing surfaces of zirconia. In the aggressive oral environment with $\mathrm{pH}$ change, temperature alterations, presence of water and constant cyclic stresses, zirconia failures could be observed at localized areas of high stress concentration on the ceramic surface or within the microstructure (Chevalier et al., 2007; Lughi and Sergo, 2010).

Zirconia is polymorphic and exists in several major phases, namely monoclinic $(m)$, tetragonal $(t)$ and cubic phase $(c)$. The $c$ phase has moderate mechanical properties and is stable up to $2680^{\circ} \mathrm{C}$, wheras the $m$ phase presents reduced mechanical performance and less density compared to other phases and it is stable up to $1170^{\circ} \mathrm{C}$. The $t$ phase on the other hand, 
provides superior mechanical properties and is stable up to $2370^{\circ} \mathrm{C}$ (Denrry and Kelly, 2008). Due to the metastability of manufactured zirconia (Li and Watanabe, 1998), stabilizing oxides $\left(\mathrm{CaO}, \mathrm{MgO}, \mathrm{CeO}_{2}, \mathrm{Y}_{2} \mathrm{O}_{3}\right)$ are added that preserve zirconia crystals in the tetragonal configuration after heating and fusing (Kobayashi et al., 1981), also preventing spontaneous transformation into the thermodynamically stable monoclinic phase (Scurria and Powers, 1994). Although zirconia is densely sintered with minimal voids, flaws and cracks, phase transformation from the $t$ into the $m$ phase could occur upon external stress application (Jung, 2002) or aging (Bottino et al., 2006). The transformation causes a volume expansion of $3-4 \%$, creating a compressive layer. This layer opposes the propagation of cracks and affects the mechanical properties of zirconia positively (Martinez-Gomis et al., 2003). However, this advantage is lost when the depth of the defects introduced is greater than that of the compressive layer, resulting in higher levels of tensile stresses, susceptibility to surface damage and an increase of the surface roughness (Glavina et al., 2004).

Stress with subsequent phase transformation could occur in zirconia after surface treatments, including machining, air-borne particle abrasion (Shukla and Seal, 2004) and clinical adjustments after cementation using burs and/or polishing instruments (Cales et al., 1994; Haraguchi et al., 2001). Adjustments with discs or burs are known to induce surface damage in the form of scratches and lateral subsurface cracks by dislocation gliding resulting in complete change in the crystal structure and formation of amorphous phases (Albakry et al., 2003). Current polishing instruments available for ceramics are often advised to be used sequentially at various rotations per minute (rpm) from rough to fine, and are usually available as silicone carbide, diamond or aluminum oxide impregnated rubbers or burs. According to the results of some in vitro studies, smooth surfaces could be obtained by using rubber polishers coated with 
diamond abrasive particles (Al-Haj Husain and Özcan, 2016) or diamond polishing pastes (Kosmac et al., 1999; Mochales et al., 2011). Polishers in disc shapes have also been described as an efficient polishing method for glassy matrix ceramics (Kailer et al., 1999; Kosmac et al., 2008). Polishing ceramic materials is known to decrease the surface roughness and thereby, cause less wear in the opposing enamel (Elmaria et al., 2006). In fact, polished zirconia was reported to cause even less wear of opposing enamel than the enamel opposing enamel (Olivera et al., 2006).

The stress-induced martensitic phase transformation and phase compositions can be analyzed using X-ray diffraction analysis (XRD) or Raman spectroscopy. XRD is a method for the quantitative evaluation of phase transformation commonly used for large areas, providing characterization of the overall sample behavior (Srinivasan et al., 1992). In previous studies with XRD-diffraction analyses usually only one polishing regimen within each study was employed, where polishing was accomplished manually and the phase transformation was quantified after low temperature degradation (Jung 2002; Janyavula et al 2013).

The objectives of this study therefore were to investigate the effect of different polishing regimens simulating the clinical workflow on surface topography and phase transformation of monolithic zirconia. The null hypotheses tested were that polishing regimens would not show significant difference in terms of a) topographical and b) chemical changes in zirconia.

\section{Material and methods}

\subsection{Specimen preparation}


Specimens were cut from small grain size $(<0.5 \mu \mathrm{m})$ zirconia blocks (Katana Zirconia HT, Kuraray-Noritake, Aichi, Japan) (Chemical composition: $\mathrm{ZrO}_{2}, \mathrm{Y}_{2} \mathrm{O}_{3}$; flexural strength: $>900$ $\mathrm{MPa}$; fracture thoughness: $5 \mathrm{MPa} \sqrt{\mathrm{m}}$ ) using an electrical precision diamond wire saw with blade diameter of $0.17 \mathrm{~mm}$ and $30 \mu \mathrm{m}$ roughness under constant water cooling (Well, Walter Ebner, Locle, Switzerland). The surfaces of the sectioned specimens were polished with $2400 \mu \mathrm{m}$ grit silicon carbide paper (Streuers, Willich, Germany) under water-cooling until a flat surface was obtained. The thickness was verified with a digital micrometer (Mitutoyo, Kamagawa, Japan). The specimens were then sintered in a high-temperature furnace (Nabertherm LHT02L16, Nabertherm $\mathrm{GmbH}$, Bremen, Germany) at $1500^{\circ} \mathrm{C}$ for $7 \mathrm{~h}$ according to the manufacturer's instructions. Finally, specimens of $12 \mathrm{~mm} \times 12 \mathrm{~mm} \times 1.8 \mathrm{~mm}$ were obtained after sintering.

\subsection{Initial polishing and grinding}

All specimens were initially finished with silicone carbide discs (Abramin, Struers, Ballerup, Denmark) of $25 \mu \mathrm{m}$ for 2 min using a lubricant (Diluant, Presi, Leocole, Switzerland), followed by $15,9,6,3$ and $1 \mu \mathrm{m}$ discs in sequence for 4 min each using a suspension (Diamond Spray Suspension, DP, Struess) at $250 \mathrm{rpm}$. A custom made device (The Dhriller ${ }^{\mathrm{TM}}$, University of Zurich, Switzerland, Designer: M.Ö.) was constructed to achieve controlled grinding and polishing procedures that could operate under different rpm and pressure levels where high and slow speed handpieces (Intramatic Lux 700KL, KaVo Dental AG, Brugg, Germany) could be connected to the dental unit (KaVo Esthetica Comfort 1065, KaVo Dental AG). The device allowed controlled movement of the handpiece bidirectional horizontally at the given trace of movement in millimetres upon the specimen that is fixed in a metal holder. The device could allow the handpiece to apply constant load of 120 to $750 \mathrm{~g}$ depending on the purpose (Fig. 1). Throughout the finishing procedures, the grinding and polishing instruments were positioned 
parallel to the specimen surfaces. The polished zirconia specimens were ground with $220 \mu \mathrm{m}$ grit diamond rotatory burs with shoulder edge (Diameter: $0.13 \mathrm{~mm}$, Length: $12 \mathrm{~mm}$, FG 5410L/6, Intensiv, Montagnola, Switzerland) at $160.000 \mathrm{rpm}$ using the high-speed hand-piece for $10 \mathrm{~s}$. After the grinding procedures, the specimens were ultrasonically cleaned (Bransonic Ultrasonic Cleaner 3510, Branson, Danbury, USA) in isopropanol for $10 \mathrm{~min}$.

\subsection{Final polishing procedures}

The grinded zirconia specimens were randomly allocated to 5 groups depending on the polishing systems to be studied, namely BG: Silicone carbide polishers (Brownie, Greenie, Super Greenie, Shofu, Ratingen, Germany); CG: Diamond impregnated ceramic polisher kit (Ceragloss, Edenta, St. Gallen, Switzerland); EV: Synthetically bonded grinder interspersed with diamond (EVE Kit, EVE, Pforzheim, Germany); SL: Urethane coated paper with aluminium oxide grits (Soflex Finishing and Polishing System Kit, 3M ESPE, St. Paul, MN, USA) and DB: Diamond bur (8 $\mu \mathrm{m}, \mathrm{FG} 9205 / 6$, Intensiv) (Table 1).

Three samples of each group for BG, EV, SL and DB were polished separately. Each step in all polishing systems was performed for $10 \mathrm{~s}$ using a slow-speed hand-piece under watercooling (50 $\mathrm{ml} / \mathrm{min}$ ), except for SL (Table 2). Polishing was performed in a custom made device under $750 \mathrm{~g}$ load, with rpm ranging between 5.000 and 30.000 depending on the manufacturer's instructions. For DB, a high-speed hand piece was used at $75.000 \mathrm{rpm}$. The specimens were cleaned ultrasonically for 10 minutes in isopropanol after each step.

\subsection{Surface topography analysis}


The mean roughness (Roughness Average: $\mathrm{Ra}$ ), the arithmetic average of the absolute values of the roughness profile ordinates, were calculated:

$$
\begin{aligned}
& \mathrm{R}_{\mathrm{a}}=\frac{1}{1} \int_{0}^{1}|Z(X)| d x \\
& \mathrm{Z}(\mathrm{x})=\text { profile ordinates of roughness profile }
\end{aligned}
$$

The surface roughness was measured using a contact profilometer (PerthometerS2, Mahr, Gottingen, Germany) and the corresponding software program (MarSurfXR 20, Mahr) at the following settings: transverse length: $2.4 \mathrm{~mm}$, standard critical wavelength: $0.25 \mathrm{~mm}$, velocity: $0.1 \mathrm{~mm} / \mathrm{s}$.

\subsection{Surface characterization}

Surface characterization of baseline and polished zirconia were performed by scanning electron microscopy (SEM) (SEM, Zeiss MERLIN Field Emission SEM, Carl Zeiss NTS GmbH, Oberkochen, Germany) and energy dispersive spectroscopy (EDS) (SEM, Zeiss MERLIN Field Emission SEM). The specimens were cleaned using an ultrasonic cleaner and dried in a vacuum desiccator. They were then mounted on aluminium stubs and viewed under the SEM. Micrographs of different microstructural components were captured at different magnifications in secondary electron mode. EDS analysis determined the changes in the elemental composition of the zirconia surface after polishing.

\subsection{Phase transformation analysis}

Phase transformation analysis of the zirconia was carried out using the Bragg Brentano X-ray diffraction analysis (XRD) (Bruker D8 Advance, Bruker Corp., Billerica, MA, USA) where the 
diffractometer was used with $\mathrm{Cu} \mathrm{Ka}$ radiation at $40 \mathrm{~mA}$ and $45 \mathrm{kV}$ and the detector was rotated between $20-40^{\circ}$ with a step of $0.02^{\circ} 2 \theta$ and step time of 0.8 degrees $/ \mathrm{min}$. The specimens were analyzed at 15 spins per minute. After establishing the main peak for the phase under test, further analysis was performed between $28-32^{\circ}$ with a step of $0.02^{\circ} 2 \theta$ and step time of 0.2 degrees/min. Phase identification was accomplished using a search-match software indexing the peaks against Power Diffraction Files (PDF) and the data were provided by International Centre for Diffraction Data (ICDD, Newtown Square, PA, USA). The monoclinic phase transformation following grinding and polishing regimens was evaluated according to the method described by Toraya et al. (1984) from the integral intensities of the monoclinic (-111)M and (111)M, and the tetragonal (101)T peaks obtained from the X-ray diffractograms.

\subsection{Statistical analysis}

Data were analyzed using a statistical software package (SPSS Software V.20, Chicago, IL, USA). Kolmogorov-Smirnov and Shapiro-Wilk tests were used to test normal distribution of the data. Statistical analysis was performed using using one-way ANOVA and Sheffe post-hoc tests. $P$ values less than 0.05 were considered to be statistically significant in all tests.

\section{Results}

The highest roughness was obtained with the EV system $(1.11 \mu \mathrm{m})$ compared to those of other systems $(0.13-0.4 \mu \mathrm{m})(p<0.05)$ (Fig. 2). Except for EV $(p<0.05)$, all polishing regimens 
produced no significant difference compared to the baseline specimens $(p>0.05)$ (control). Compared to GB, DB and BG decreased the mean roughness, yet being not significant $(p>0.05)$.

SEM micrographs indicated specimens with smooth surface at baseline and with evident scratches after grinding procedures (Figs. 3a-g). The studied polishing regimens left traces of grooves at varying degrees with EV showing deeper morphology. BG and CG presented visually less number ad disribution of grooves but none of the systems eliminated the grooves completely.

XRD plots exhibited a main peak of tetragonal zirconia at baseline (ICDD: 01-070-4432) at $30.13^{\circ} 2 \theta$ and a minor peak at $34.94^{\circ} 2 \theta$ (Fig. 4). Thus, further scans were performed between $28-32^{\circ} 2 \theta$ (Fig. 5).

The polishing regimes resulted in peak shifts in zirconia at baseline. While GB, CG, EV, SL and DB exhibited a peak shift to the left, BG demonstrated a right peak shift on the $2 \theta$ scale. No monoclinic phase change was noted after any of the polishing systems.

Compared to baseline specimens (03.02wt\%; 00.66 at\%), EDS analysis showed increased weight and atomic percentages of yttrium for each polishing method (04.93-05.35 wt\%; 01.4101.63 At\%), except for BG (02.3 wt\%; 00.45 At\%) (Figs. 6a-f).

\section{Discussion}

This study was undertaken in order to study the effect of different polishing regimens simulating the clinical workflow on surface topography and phase transformation of monolithic zirconia. Based on the results of this study, since polishing systems studied showed significant difference in terms of surface roughness, the first hypothesis could be rejected. However, phase 
transformation was not noted after the studied polishing regimens yielding to acceptance of the second hypothesis.

In this study, unlike manual preparation, the grinding and polishing procedures were performed using a custom made device in an attempt to standardize the surface preparation. When grinded with a fine bur, zirconia may show improved mechanical properties but coarse grinding (>150 mm grit) causes decrease in flexural strength and long-term stability of zirconia (Kosmac et al., 2000). On the other hand, polishing reduces the strain on the surface and was therefore reported to reduce the strength of zirconia (Garvie et al., 1975). The objective of this study did not involve investigating mechanical properties of zirconia after polishing but focused on roughness of the surface. The outcomes of a clinical study indicated enamel wear of $10 \mu \mathrm{m}$ and zirconia material of $33 \mu \mathrm{m}$ within an observation duration of only 6 months (Stober et al., 2014). In this study, BG having silicone carbide particles possibly presented more compact structure due to the binding material and thereby resulted in smooth surfaces, whereas EV and CG containing diamond particles resulted in more damage and loss of particles on the polishing instruments (Al-Haj Husain and Özcan, 2016). Eventually, the efficacy of the EV and CG due to loss of particles was limited when polishing hard zirconia substrate. It can be thus stated that not only the roughness of the polishing instrument itself but also the integrity of the surface texture dictates the effective polishing on zirconia surface.

Zirconia is completely crystalline thus phase changes within the material could be assessed by $\mathrm{XRD}$ analysis. The change of the crystal structure is however dependent on the grit-size, magnitude and speed of load applied and thermal conductivity of zirconia. Surface manipulation conducted during polishing adjustments may result in local heating leading to $t$ to $m$ phase transformation (Juy and Anglada, 2007). In previous studies, calorimetric surface energy 
enthalpy measurements showed that the average surface energy of the $t$ phase is lower than that of the $m$ phase (Garvie, 1965; Toraya et al., 1984). Nevertheless, it has to noted that the stability of a given nucleus or small cluster is specified by the balance between the free energy of formation, being favourable to the nucleus formation, and the work prearranged by the new surface (unfavourable) (Garvie, 1965; Toraya et al., 1984). Apparently, lower surface energies will favour the formation of the metastable crystals in zirconia with lower grain sizes (Garvie, 1965; Toraya et al., 1984). Accordingly, in this study, an initial diffractogram at a wide range of the 2-theta scale was performed on the baseline material in order to assess the location of the main peak. The results indicated $t$ phase of zirconia. A slower scan was then performed on all specimens at lower angles to assess the peak shifts and phase changes. The grinding and all polishing methods except BG system exhibited a peak shift to the left thus towards the lower angles of the 2-theta scale. Peak shifts are usually caused by strains to the crystal lattice whereas shifts to lower angles are caused by an expansion of the crystal lattice typically caused by compressive forces. According to the analysis, BG polishing system resulted in a peak shift to higher angles thus the crystal lattice was compressed by a tensile stress. Since the peak shifts were in the order of fractions of an angle they can be attributed to stress rather than a phase change in the material.

Employing the best polishing protocol causing the least phase transformation is assumed to eventually diminish opposing enamel wear and plaque accumulation that could also be a setback depending on the location of the rough surface on the FDP. Although, all polishing regimens tested decreased surface roughness when compared to the grinded specimens, none of the polishing regimens restored the same smooth surface achieved at baseline zirconia. Since such adjustments are made after cementation, unfortunately, glaze layer application is not 
possible. Hence, the clinicians have to accept the fact that when monolithic zirconia is indicated, premature contact removal with burs followed by polishing using different instruments with different coatings would still leave some traces that may be detrimental for the wear of opposing dentition. In this study, no glaze layer was applied on the zirconia specimens that could be considered as a limitation of this study and needs further investigations. The grain size of the zirconia tested in this study was $<0.5 \mu \mathrm{m}$. Zirconia materials with larger grain size may cause more roughness due to possible grain pull out during finishing and polishing protocols. Nevertheless, the findings of this study denoted that polishing causes stress on zirconia rather than a phase change in the material itself. Future studies should also focus on mechanical properties of monolithic zirconia after polishing regimens.

\section{Conclusions}

From this study, the following could be concluded:

1. The EV polishing regimen caused the roughest surface topography on monolithic zirconia compared to other polishing systems tested.

2. None of the polishing regimens restored the surface roughness of zirconia to the baseline situation.

3. All polishing methods, except BG, exhibited a peak shift towards the lower angles of the 2theta scale according to the XRD anaylsis. Since the peak shifts were in the order of fractions of an angle they are attributed to stress formation rather than a phase change in the material. Thus, all polishing systems tested may not be detrimental for phase transformation of monolithic zirconia tested. 


\section{Clinical Relevance}

For intraoral polishing of monolithic zirconia after cementation and adjustments, BG polishing system could be recommended as it created the least surface roughness and least stress formation on zirconia among the polishing systems studied.

\section{Acknowledgements}

The authors acknowledge Mr. Albert Trottmann, University of Zürich, Center for Dental and Oral Medicine, Zürich, Switzerland, for his assistance with the specimen preparation, Mr. Christian Lüscher for his support with the development of the custom made device. Intensive AS, Montagnola, Switzerland for generous provision of the burs and polishing kits. Ing. James Camilleri of the Department of Metallurgy and Materials Engineering, Faculty of Engineering, University of Malta for his help with the analysis. ERDF (Malta) for the financing of the testing equipment through the project: "Developing an Interdisciplinary Material Testing and Rapid Prototyping R\&D Facility" (Ref. no. 012).

\section{Conflict of interest}

The authors did not have any commercial interest in any of the materials used in this study. 


\section{References}

Albakry M, Guazzato M, Swain M. Effect of sandblasting, grinding, polishing and glazing on the flexural strength of two pressable all-ceramic dental materials. J Dent 2003;32:91-99.

Al-Haj Husain N, Özcan M. A study on topographical properties and surface wettability of monolithic zirconia after use of diverse polishing instruments with different surface coatings. $J$ Prosthodont 2016 (Epub).

Bottino MC, Valandro LF, Kantorski KZ, Bressiani JC, Bottino MA. Polishing methods of an alumina-reinforced feldspar ceramic. Braz Dent J 2006;17:285-289.

British Standards Institution. BSI ENV 843-4. Advanced technical ceramics. Monolithic ceramics. Mechanical properties at room temperatures. Vickers, Knoop and Rockwell superficial hardness tests, 1995.

Cales B, Stefani Y, Lilley E. Long-term in vivo and in vitro aging of a zirconia ceramic used in orthopaedy. J Biomed Mater Res 1994;28:619-624.

Chevalier J, Gremillard L, Deville S. Low-temperature degradation of zirconia and implications for biomedical implants. Ann Rev Mater Res 2007;37:2986-2993.

Christel P, Meunier A, Heller M, Torre JP, Peille CN. Mechanical properties and short-term invivo evaluation of yttrium-oxide-partially-stabilized zirconia. J Biomed Mater Res 1989;23:45-61.

Denry I, Kelly JR. State of the art of zirconia for dental applications. Dent Mater 2008;24:299307. 
Elmaria A, Goldstein G, Vijayaraghavan T, Legeros RZ, HIttelman EL. An evaluation of wear when enamel is opposed by various ceramic materials and gold. J Prosthet Dent 2006;96:345353.

Garvie RC. The occurrence of metastable tetragonal zirconia as a crystallite size effect. J Physic Chem 1965;69:1238-1243.

Garvie RC, Hannink RH, Pascoe RT. Ceramic steel. Nature 1975;258:703-704.

Glavina D, Skrinjaric I, Mahovic S, Majstorovic M. Surface quality of Cerec CAD/CAM ceramic veneers treated with four different polishing systems. Eur J Paediat Dent 2004;5:30-34 .

Guazzato M, Albakry M, Ringer SP, Swain MV. Strength, fracture toughness and microstructure of a selection of all ceramic materials. Part I: pressable and alumina glass-infiltrated ceramics. Dent Mater 2004;20:441-448.

Haraguchi K, Sugano N, Nishii T, Mlki H, Oka K, Yoshikawa H. Phase transformation of a zirconia ceramic head after total hip arthroplasty. J Bone Joint Surg 2001;83:996-1000.

Janyavula S, Lawson N, Cakir D, Beck P, Ramp LC, Burgess JO. The wear of polished and glazed zirconia against enamel. J Prosthet Dent 2013;109:22-29.

Jung M. Finishing and polishing of a hybrid composite and a heat-pressed glass ceramic. Oper Dent 2002;27:175-183.

Juy A, Anglada M. Surface phase transformation during grinding of Y-TZP. J Am Ceramic Soc 2007;90:2618-2621. 
Kailer A, Nickel K, Gogotsi Y. Raman microspectroscopy of nanocrystalline and amorphous phases in hardness indentations. J Raman Spect 1999;30:939-946.

Kelly JR, Denry I. Stabilized zirconia as a structural material. Dent Mater 2008;24:289-298.

Kobayashi K, Kuwajima $\mathrm{H}$, Masaki T. Phase change and mechanical properties of $\mathrm{ZrO}_{2}-\mathrm{Y}_{2} \mathrm{O}_{3}$ solid electrolyte after ageing. Solid State Ion 1981;3:489-495.

Kosmac T, Oblak C, Jevnikar P, Funduk N, Marion L. The effect of surface grinding and sandblasting on flexural strength and reliability of Y-TZP zirconia ceramic. Dent Mater 1999;15:426-433.

Kosmac T, Oblak C, Jevnikar P, Funduk N, Marion L. Strength and reliability of surface treated Y-TZP dental ceramics. J Biomed Mater Res 2000;53:304-313.

Kosmac T, Oblak C, Marion L. The effect of dental grinding and sandblasting on ageing and fatigue behavior of dental (Y-TZP) ceramics. J Eur Ceram Soc 2008;28:1085-1090.

Li J-F, Watanabe R. Phase transformation in Y2O3-partially-stabilized ZrO2 polycrystals of various grain sizes during low-temperature aging in water. J Am Ceram Soc 1998;81:26872778.

Lilley E. Review of low temperature degradation in Y-TZPs. In: Tressler RE, McNallan M, editors. Ceramic transaction: corrosion and corrosive degradation of ceramics. Westerville: American Ceramics Society 1990, pp. 87-407.

Lughi $\mathrm{V}$, Sergo $\mathrm{V}$. Low temperature degradation aging of zirconia: A critical review of the relevant aspects in dentistry. Dent Mater 2010;26:807-820.

Manicone PF, Rossi lommetti P, Raffaelli L. An overview of zirconia ceramics: Basic properties and clinical applications. J Dent 2007;35:819-826. 
Martínez-Gomis J, Bizar J, Anglada JM, Samso J, Peraire M. Comparative evaluation of four finishing systems on one ceramic surface. Int J Prosthodont 2003;16;74-77.

Mochales C, Maerten A, Rack A, Cloetens P, Mueller WD, Zaslansky P, Fleck C. Monoclinic phase transformations of zirconia-based dental prostheses, induced by clinically practised surface manipulations. Acta Biomater 2011;7:2994-3002.

Nakamura K, Harada A, Inagaki R, Kanno T, Niwano Y, Milleding P, Örtengren U. Fracture resistance of monolithic zirconia molar crowns with reduced thickness. Acta Odontol Scand 2015;73:602-608.

Olivera $\mathrm{AB}$, Matson $\mathrm{E}$, Marques MM. The effect of glazed and polished ceramics on human enamel wear. Int J Prosthodont 2006;19:547-548.

Probster L, Diehl J. Slip-casting alumina ceramics for crown and bridge restorations. Quintessence Int 1992;23:25-31.

Raigrodski AJ, Hillstead MB, Meng GK, Chung KH. Survival and complications of zirconiabased fixed dental prostheses: a systematic review. J Prosthet Dent 2012;107:170-177.

Scurria MS, Powers JM. Surface roughness of two polished ceramic materials. J Prosthet Dent 1994;71:174-177.

Shukla S, Seal J. Thermodynamic tetragonal phase stability in sol-gel derived nano domains of pure zirconia. J Physic Chem B 2004;108:3395-3399.

Srinivasan R, Davis BH, Cavin OB, Hubbard CR. Crystallization and phase-transformation process in zirconia-an in situ high temperature X-ray-diffraction study. J Am Ceram Soc 1992;75:1217-1222.

Stober T, Bermejo JL, Rammelsberg P, Schmitter M. Enamel wear caused by monolithic zirconia crowns after 6 months of clinical use. J Oral Rehabil 2014;41:314-322. 
Toraya $\mathrm{H}$, Yoshimura $\mathrm{M}$, Somiya $\mathrm{S}$. Calibration curve for quantitative analysis of the monoclinic-tetragonal $\mathrm{ZrO}_{2}$ system by X-ray diffraction. J Am Ceram Soc 1984;67:C-119-C121.

\section{Captions to tables and figures:}

\section{Figures:}

Fig. 1 Monolithic zirconia specimen in the holder of the custom made device in relation to the bur.

Fig. 2 Mean roughness of zirconia surface after grinding and various polishing regimens.

Figs. 3a-g Secondary scanning electron micrographs (SEM) of monolithic zirconia after being subjected to the different polishing regimens, a) baseline, b) GB, c) BG, d) CG, e) EV, f) SI, g) DB. For group abbreviations see Table 1.

Fig. 4 X-ray diffraction plot of zirconia specimen at baseline showing the main peaks located at approximately 30 and $35^{\circ} 2 \theta$.

Fig. 5 X-ray diffraction plots of zirconia specimen at baseline, after grinding and polishing regimens showing peak shifts along the $2 \theta$ axis indicating phase change in the material.

Figs 6a-f. EDS plots and weight and atomic per cent of the elements detected on zirconia specimens at a) baseline and after b) SL, c) BG, d) CG, e) EV, f) DB polishing regimens. 


\section{Tables:}

Table 1. Brands of grinding and polishing instruments, their manufacturers, recommended procedures, chemical composition, mechanical and physical properties and their clinical function according to the manufacturers.

Table 2. Experimental conditions for grinding and polishing steps applied on monolithic zirconia specimens. For group abbreviations see Table 1. 


\begin{tabular}{|c|c|c|c|c|c|c|c|}
\hline \multirow[t]{2}{*}{$\begin{array}{l}\text { Instrument Brands } \\
\text { (Abbreviations) }\end{array}$} & \multirow[t]{2}{*}{ Manufacturer } & \multicolumn{3}{|c|}{$\begin{array}{l}\text { Recommended procedure } \\
\text { by the manufacturer }\end{array}$} & \multirow[t]{2}{*}{$\begin{array}{l}\text { Chemical } \\
\text { composition }\end{array}$} & \multirow{2}{*}{$\begin{array}{l}\text { Mechanical and } \\
\text { and } \\
\text { physical properties }\end{array}$} & \multirow[t]{2}{*}{ Clinical function } \\
\hline & & $\begin{array}{l}\text { Rotation } \\
\text { per } \\
\text { minute } \\
\text { (Rpm) }\end{array}$ & $\begin{array}{l}\text { Water } \\
(50 \\
\mathrm{ml} / \mathrm{min})\end{array}$ & Load & & & \\
\hline Grinding bur (GB) (FG 5410L/6) & $\begin{array}{l}\text { Intensiv, } \\
\text { Montagnola, } \\
\text { Switzerland }\end{array}$ & $\begin{array}{l}55^{\prime} 000- \\
160 ’ 000\end{array}$ & Yes & $10 \mathrm{~g}$ & $\begin{array}{l}\text { Diamond particles } \\
\text { imbedded into binder } \\
\text { Matrix material }\end{array}$ & $\begin{array}{l}\text { Grit: } 220 \mu \mathrm{m} \\
\text { Diameter: } 0.13 \mathrm{~mm} \\
\text { Length: } 12 \mathrm{~mm}\end{array}$ & Finishing \\
\hline $\begin{array}{l}\text { Brownie, Greenie, Super } \\
\text { Greenie (BG) (FG 0413, FG } \\
\text { 0414, FG 414B) }\end{array}$ & $\begin{array}{l}\text { Shofu, } \\
\text { Ratingen, } \\
\text { Germany }\end{array}$ & $\begin{array}{l}5,000- \\
7,000\end{array}$ & Yes & $1-2 \mathrm{~N}$ & $\begin{array}{l}\text { Silicon carbide } \\
\text { polishers }\end{array}$ & Diameter: $0.30 \mathrm{~mm}$ & $\begin{array}{l}\text { Prepolish, polish } \\
\text { and superpolish }\end{array}$ \\
\hline $\begin{array}{l}\text { Ceragloss (CG) } \\
\text { (335 RA, } 3035 \text { RA, } 30035 \text { RA) }\end{array}$ & $\begin{array}{l}\text { Edenta, } \\
\text { St. Gallen, } \\
\text { Switzerland }\end{array}$ & $\begin{array}{l}10^{\prime} 000- \\
12^{\prime} 000\end{array}$ & Yes & & $\begin{array}{l}\text { Diamond impregnated } \\
\text { ceramic polisher kit }\end{array}$ & Length: $10 \mathrm{~mm}$ & $\begin{array}{l}\text { Finishing, } \\
\text { polishing } \\
\text { and high-lustre } \\
\text { polishing }\end{array}$ \\
\hline 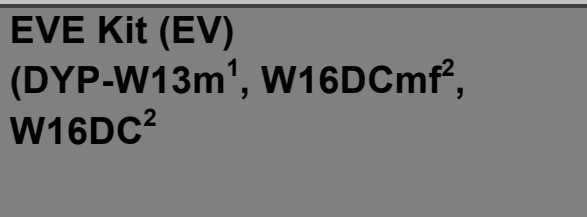 & $\begin{array}{l}\text { EVE,Pforzheim } \\
\text { Germany }\end{array}$ & $\begin{array}{l}\text { 1) } 8,000- \\
12,000 \\
\text { 2) } 7^{\prime} 000- \\
10,000\end{array}$ & Yes & & $\begin{array}{l}\text { Synthetically bonded } \\
\text { grinder interspersed } \\
\text { with diamond }\end{array}$ & $\begin{array}{l}\text { 1) } 4 \mathrm{~mm} \times 10 \mathrm{~mm} \\
\text { 2) } 6 \mathrm{~mm} \times 7.5 \mathrm{~mm}\end{array}$ & $\begin{array}{l}\text { Smoothing, } \\
\text { prepolish, } \\
\text { high-gloss polish }\end{array}$ \\
\hline $\begin{array}{l}\text { Soflex Finishing and Polishing } \\
\text { System Kit (SL) }\end{array}$ & $\begin{array}{l}\text { 3M ESPE, } \\
\text { St. Paul, MN, } \\
\text { USA }\end{array}$ & $\begin{array}{l}10^{\prime} 000 \\
30\end{array}$ & No & & $\begin{array}{l}\text { Urethane coated } \\
\text { paper with aluminium } \\
\text { oxide grits }\end{array}$ & $13 \mathrm{~mm}$ discs & $\begin{array}{l}\text { Finishing, } \\
\text { polishing }\end{array}$ \\
\hline Diamond Bur (DB) (FG9205/6) & Intensiv & $75^{\prime} 000$ & Yes & $10 \mathrm{~g}$ & $\begin{array}{l}\text { Diamond particles } \\
\text { embedded into binder } \\
\text { matrix material }\end{array}$ & $8 \mu \mathrm{m}$ & Polishing \\
\hline
\end{tabular}

Table 1. Brands of grinding and polishing instruments, their manufacturers, recommended procedures, chemical composition, mechanical and physical properties and their clinical function according to the manufacturers. 


\begin{tabular}{|c|c|c|c|c|}
\hline \multicolumn{5}{|c|}{ Experimental Conditions } \\
\hline & Rpm & Time (s) & Pressure (N) & $\begin{array}{l}\text { Water cooling } \\
\text { (50 } \mathrm{ml} / \mathrm{min})\end{array}$ \\
\hline \multicolumn{5}{|c|}{ Grinding Step } \\
\hline GB & $160 ’ 000$ & 10 & 0.75 & Yes \\
\hline \multicolumn{5}{|c|}{ Polishing Steps } \\
\hline BG (3 Steps) & $1^{\text {st }}, 2^{\text {nd }}, 3^{\text {rd }} 5^{\prime} 000$ & 30 & 0.75 & Yes \\
\hline CG (3 Steps) & $100^{\prime} 000$ & 30 & 0.75 & Yes \\
\hline EV (3 Steps) & $\begin{array}{c}1^{\text {st }} 7^{\prime} 000 \\
2^{\text {nd }} 3^{\text {rd }} 10^{\prime} 000\end{array}$ & 30 & 0.75 & Yes \\
\hline SL (4 Steps) & $\begin{array}{c}1^{\text {st }}, 2^{\text {nd }}, 3^{\text {rd }} 4^{\text {th }} \\
10^{\prime} 000\end{array}$ & 40 & 0.75 & No \\
\hline DB & $75^{\prime} 000$ & 10 & 0.75 & Yes \\
\hline
\end{tabular}

Table 2. Experimental conditions for grinding and polishing steps applied on monolithic zirconia specimens. For group abbreviations see Table 1. 
Figures:

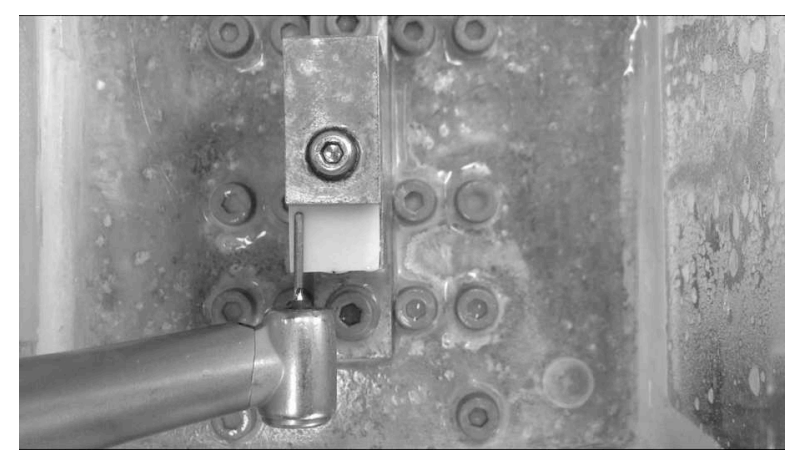

Fig. 1 Monolithic zirconia specimen in the holder of the custom made device in relation to the bur.

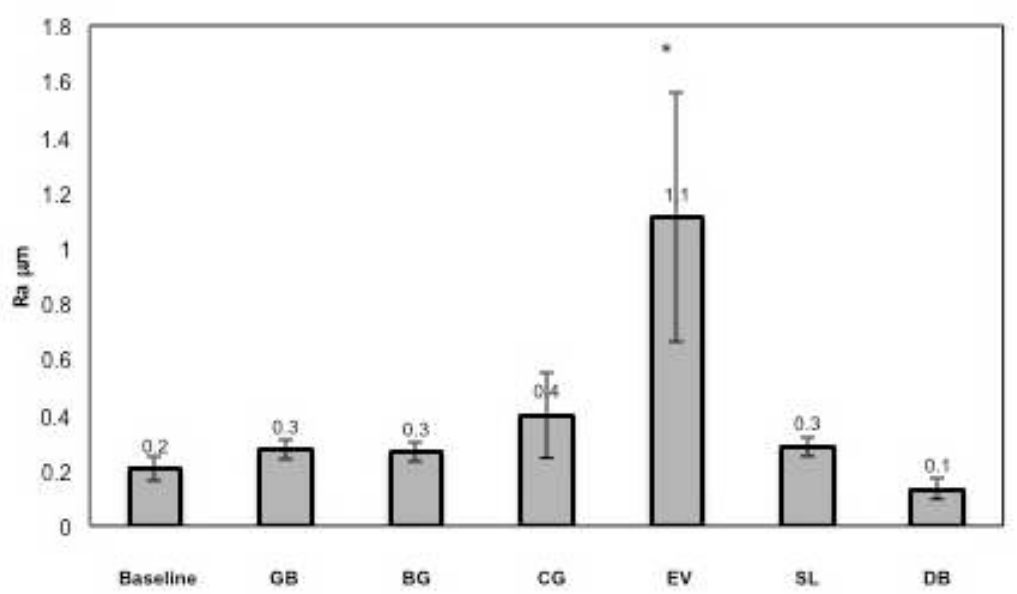

Fig. 2 Mean roughness of zirconia surface after grinding and various polishing regimens. 

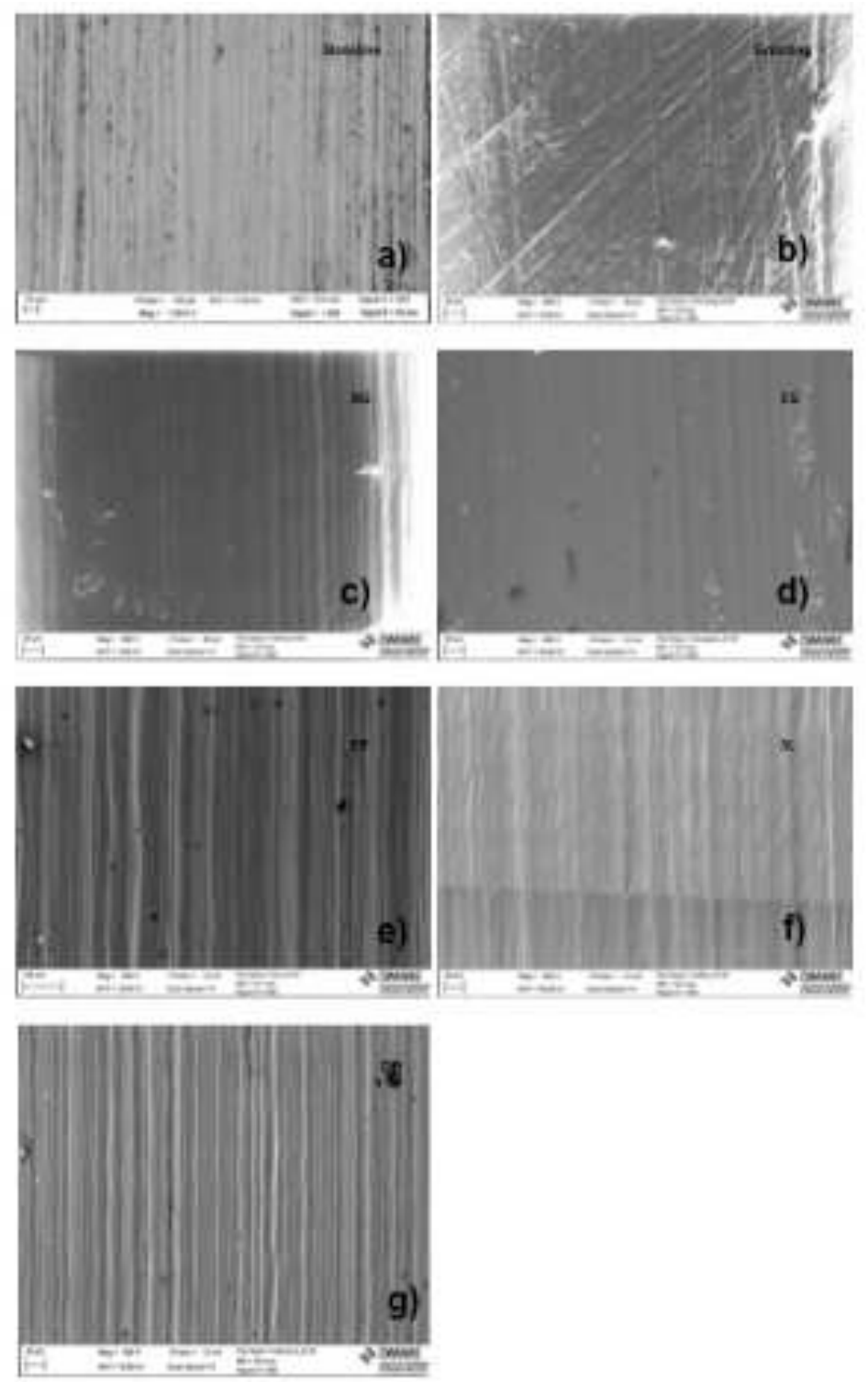

Figs. 3a-g Secondary scanning electron micrographs (SEM) of monolithic zirconia after being subjected to the different polishing regimens, a) baseline, b) GB, c) BG, d) CG, e) EV, f) SI, g) DB. For group abbreviations see Table 1. 


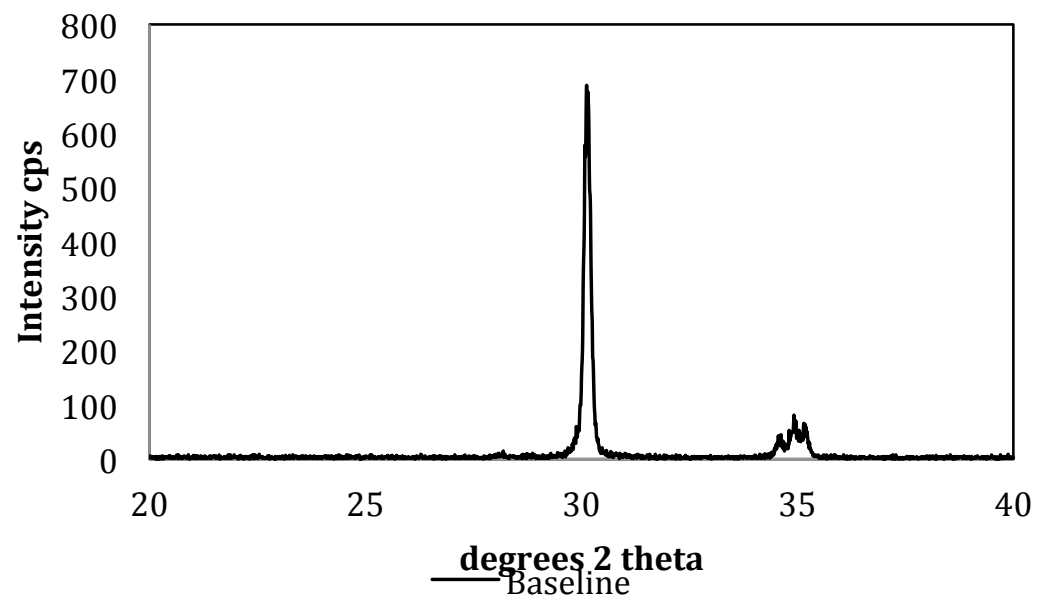

Fig. 4 X-ray diffraction plot of zirconia specimen at baseline showing the main peaks located at approximately 30 and $35^{\circ} 2 \theta$.
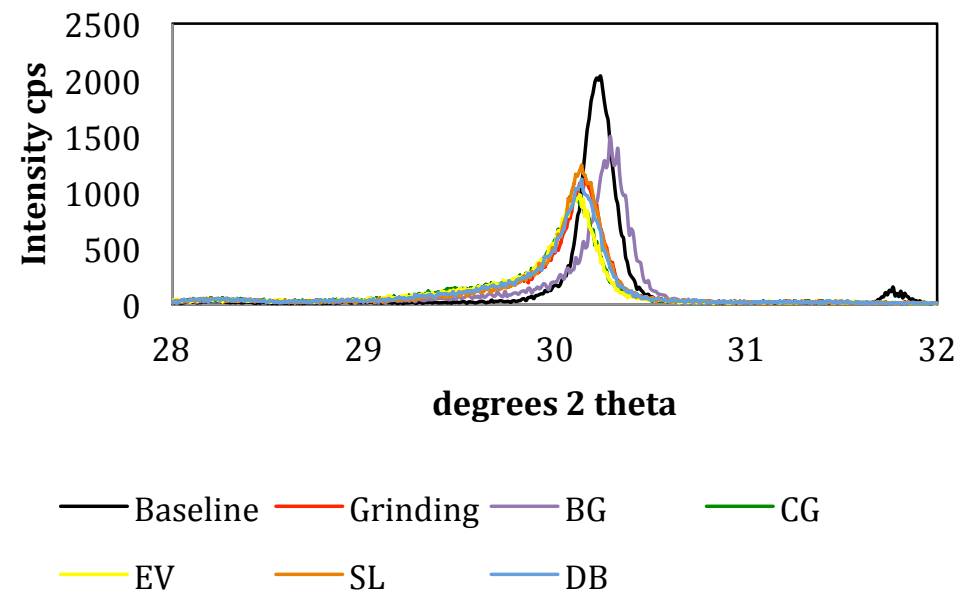

Fig. 5 X-ray diffraction plots of zirconia specimen at baseline, after grinding and polishing regimens showing peak shifts along the $2 \theta$ axis indicating phase change in the material. 


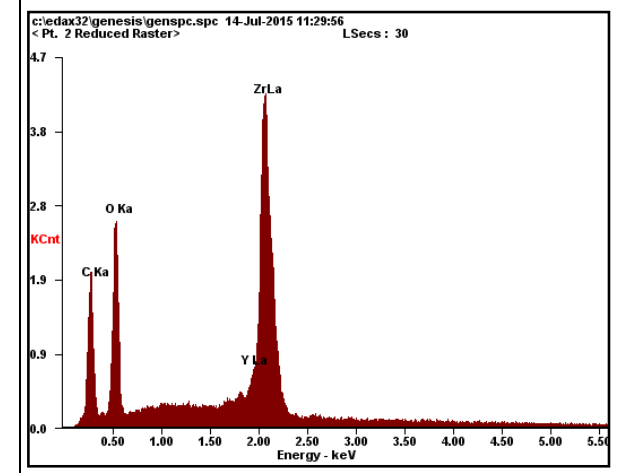

a) Baseline

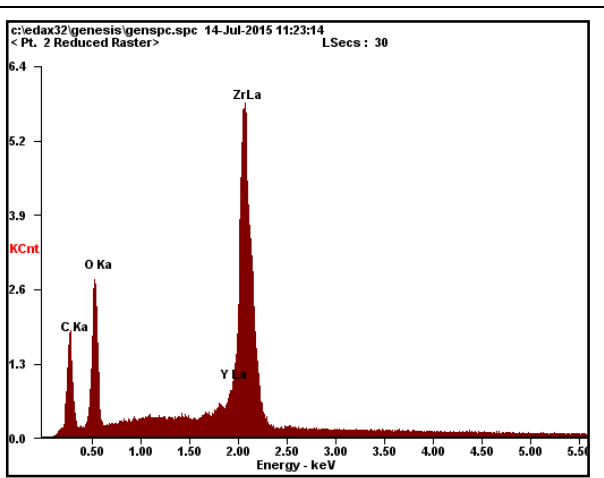

c) $B G$

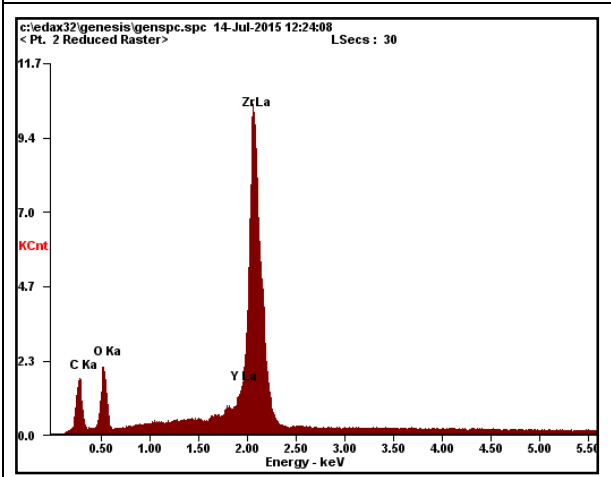

e) EV

\begin{tabular}{||l|l|l|}
\hline Element & Wt \% & At \% \\
\hline$C K$ & 30.86 & 50.18 \\
\hline$O K$ & 34.77 & 42.44 \\
\hline$Y L$ & 03.02 & 00.66 \\
\hline$Z r L$ & 31.35 & 06.71 \\
\hline
\end{tabular}

b) $\mathrm{SL}$

\begin{tabular}{||l|l|l|}
\hline Element & Wt \% & At \% \\
\hline$C K$ & 35.03 & 51.03 \\
\hline$O K$ & 40.48 & 44.26 \\
\hline$Y L$ & 02.30 & 00.45 \\
\hline$Z r L$ & 22.19 & 04.26 \\
\hline
\end{tabular}

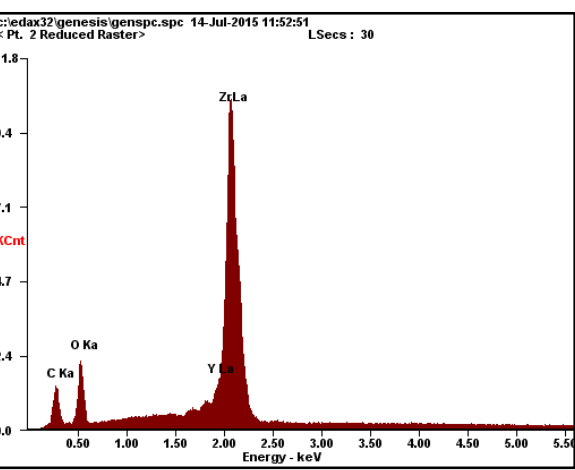

d) $C G$

\begin{tabular}{|l|l|l|}
\hline Element & Wt \% & At \% \\
\hline$C K$ & 23.94 & 50.78 \\
\hline$O K$ & 21.28 & 33.89 \\
\hline$Y L$ & 04.93 & 01.41 \\
\hline$Z r L$ & 49.85 & 13.92 \\
\hline
\end{tabular}

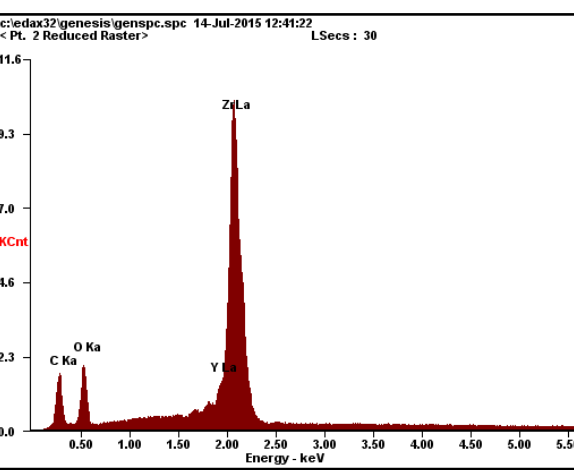

f) $\mathrm{DB}$

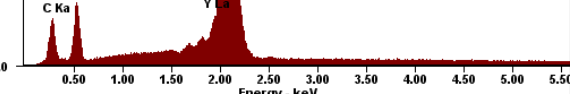

\begin{tabular}{|l|l|l|}
\hline Element & Wt \% & At \% \\
\hline$C K$ & 21.49 & 48.05 \\
\hline$O K$ & 20.81 & 34.93 \\
\hline$Y L$ & 05.25 & 01.58 \\
\hline$Z r L$ & 52.45 & 15.44 \\
\hline
\end{tabular}

\begin{tabular}{|l|l|l|}
\hline Element & Wt \% & At \% \\
\hline$C K$ & 19.96 & 45.04 \\
\hline$O K$ & 22.28 & 37.75 \\
\hline$Y L$ & 05.35 & 01.63 \\
\hline$Z r L$ & 52.41 & 15.57 \\
\hline \hline
\end{tabular}

\begin{tabular}{|l|l|l||}
\hline Element & Wt \% & At \% \\
\hline $\boldsymbol{C} K$ & 24.63 & 51.74 \\
\hline $\boldsymbol{O} K$ & 21.06 & 33.21 \\
\hline $\boldsymbol{Y} \boldsymbol{K}$ & 05.11 & 01.45 \\
\hline$Z \boldsymbol{r} L$ & 49.19 & 13.60 \\
\hline \hline
\end{tabular}

Figs 6a-f. EDS plots and weight and atomic per cent of the elements detected on zirconia specimens at a) baseline and after b) SL, c) BG, d) CG, e) EV, f) DE polishing regimens. 